\title{
Modelling of circulation and dispersion of radioactive pollutants in the Japan Sea
}

\author{
Matjaž ČETINA a, Rudi RAJAR ${ }^{\text {a**, Pavel POVINEC }}{ }^{\text {b }}$ \\ ${ }^{\text {a }}$ Faculty of Civil and Geodetic Engineering, University of Ljubljana, Hajdrihova 28, 1000 Ljubljana, Slovenia \\ ${ }^{\mathrm{b}}$ International Atomic Energy Agency, MEL, Monaco
}

Received 21 February 2000; revised 11 July 2000; accepted 12 July 2000

\begin{abstract}
A large amount of radioactive waste was deposited in the Japan Sea, at a depth of about $3000 \mathrm{~m}$ by the former Soviet Union. Research was carried out to determine to what extent the surface waters could be contaminated by possible leakage from the dumped containers. A three-dimensional, non-linear, baroclinic model was used to determine the circulation and pollutant dispersion. The computations were carried out in the diagnostic mode, taking into account data on winter and summer temperature and salinity distribution. Thermohaline forcing due to strong temperatures and salinity gradients is the main forcing factor influencing the bottom circulation. Wind forcing and the inflow/outflow surface currents were also taken into account. The simulated velocity fields show relatively good agreement with observed surface currents and with some measurements of bottom currents. The simulated hydrodynamic field is in visibly closer agreement with the observed surface circulation when topographic stress is taken into account. After the release of radionuclides at the sea bottom, the first very small contamination would reach the surface layers after 3 years. The maximum concentrations of about $10^{-3} \mathrm{~Bq} \cdot \mathrm{m}^{-3}$ would be attained after 30 years. But everywhere the predicted radionuclide concentrations would be about two orders of magnitude smaller than the background values, caused by global fallout from nuclear weapons tests. Therefore, it will be impossible to determine the effect of leakage of wastes from the dumping sites over the present background levels. C 2000 Ifremer/CNRS/IRD/Éditions scientifiques et médicales Elsevier SAS
\end{abstract}

\section{hydrodynamic / 3D modelling / radioactive pollution / Japan Sea}

Résumé - Simulation des courants et de la dispersion des polluants radioactifs en mer du Japon. Une quantité importante de déchets radioactifs a été déposée en mer du Japon, à une profondeur d'environ 3000 mètres par l'ex-URSS. Une certaine inquiétude est née quant à la possibilité de voir des polluants radioactifs s'échapper des déchets déposés. La question principale est : quand et quelles concentrations pourraient être emportées par les courants et dispersées dans les couches de surface où ils contamineraient la chaîne alimentaire marine ? Un modèle tridimensionnel, non-linéaire et barocline, a été utilisé pour déterminer la circulation et la dispersion potentielles. Le module hydrodynamique est basé sur la méthode numérique des volumes finis, tandis que le module de transport-dispersion résout l'équation d'advection-diffusion par une méthode du type lagrangien, qui est sans diffusion numérique. Les simulations du type diagnostic sont faites, prenant en compte la distribution de la température et de salinité en hiver et en été. En outre, l'influence du vent et des courants à travers des détroits sont prises en compte dans les simulations. Des simulations à long-terme du transport et de la dispersion des polluants ont été exécutées avec le module transport-dispersion sur des périodes de vingt à quarante ans. Les conclusions suivantes ont été obtenues: (1) la comparaison entre les vitesses simulées et les courants de surface observés ainsi que certaines mesures des courants de profondeur valident de manière satisfaisante le modèle; (2) la circulation en profondeur est principalement influencée par la force thermohaline due à de forts gradients de température et de salinité pouvant engendrer des vitesses de l'ordre de $10 \mathrm{~cm} \mathrm{~s}^{-1}$. L'influence du vent est d'un

\footnotetext{
* Correspondence and reprints.

E-mail address: rrajar@fagg.uni-lj.si (R. Rajar).
}

(C) 2000 Ifremer/CNRS/IRD/Éditions scientifiques et médicales Elsevier SAS. Tous driots réservés. 
ordre de grandeur inférieur, bien qu'elle puisse influencer la circulation de surface. (3) La circulation simulée est en accord plus étroit avec la circulation observée lorsque la contrainte topographique est prise en compte. (4) Les résultats finaux, montrent qu'une première contamination légère, atteindrait les eaux de surface en trois ans. Les concentrations maximums, qui seraient d'environ $10^{-3} \mathrm{~Bq} \mathrm{~m}^{-3}$, seraient atteintes en trente ans. Mais partout, la contamination radioactive serait inférieure au niveau de contamination globale, d'au moins de deux ordres de grandeur. (C) 2000 Ifremer/CNRS/IRD/Éditions scientifiques et médicales Elsevier SAS

\section{hydrodynamique / modélisation 3D / pollution radioactive / mer du Japon}

\section{INTRODUCTION}

The Japan Sea is a large, almost enclosed sea between the Japanese islands, Sakhalin Island, the Siberian coast and Korea. Its length is about $1800 \mathrm{~km}$, the width $900 \mathrm{~km}$ (see figure 1) and the maximum depth is about $3900 \mathrm{~m}$. The surface area is $1.01 \times 10^{6} \mathrm{~km}^{2}$ and the volume $1.36 \times 10^{6} \mathrm{~km}^{3}$ (Ketchum, 1983). The relatively weak exchange of water with the Pacific Ocean is enabled through four straits and is described in section three. A large amount of solid radioactive wastes was deposited by the former Soviet Union at the sea bottom, at a depth of about $3000 \mathrm{~m}$ at several locations, mainly at stations 6,9 and 10 off Vladivostok (figure 1). The dumped solid wastes consisted of four reactor vessels of nuclear submarines deposited without spent nuclear fuel (178 $\mathrm{TBq})$ as well as wastes packed in containers (129 TBq). The total activity dumped from 1968-1992 was about $307 \mathrm{TBq}$ (Peterson et al., 1995). The composition of radionuclides in the dumped wastes is not well known. The main contributors are expected to be ${ }^{60} \mathrm{Co},{ }^{137} \mathrm{Cs},{ }^{55} \mathrm{Fe}$ and ${ }^{90} \mathrm{Sr}$. Due to the decay of radionuclides (mainly ${ }^{60} \mathrm{Co}$, ${ }^{55} \mathrm{Fe}$, etc.), the present activity of dumped wastes is estimated to be much lower, about $14 \mathrm{TBq}$ (Povinec et al., in preparation). With the aging (corrosion) of containers and reactor vessels, radionuclides from the wastes could be released to the marine environment. The estimated present release rates (for all radionuclides together) are about $3 \mathrm{TBq}$ year $^{-1}$. The most important radionuclides which could be released from the wastes are ${ }^{137} \mathrm{Cs}$ and ${ }^{90} \mathrm{Sr}$. For modelling purposes, a hypothetical release of the unit of activity $1 \mathrm{TBq}$ of ${ }^{137} \mathrm{Cs}$ for 90 days was assumed, at location 9 (approx. $134^{\circ} \mathrm{E}, 41^{\circ} 40^{\prime} \mathrm{N}$ ), which should be a very conservative approach. As the ${ }^{137} \mathrm{Cs}$ half life is about thirty years and caesium is a conservative tracer, no corrections for decay or caesium scaveng- ing from the water column have been applied during the simulations. A similar hypothetical scenario can be applied for ${ }^{90} \mathrm{Sr}$. As ${ }^{60} \mathrm{Co}$ and ${ }^{55} \mathrm{Fe}$ have much shorter half lives (5.3 and 2.6 years, respectively), they were not used in the modelling scenario. A detailed description of the radionuclide inventories and possible release rate scenarios will be presented in a separate paper.

Although several measurements of radionuclide concentration in this sea have shown no increase of radioactivity over the background values (Hirose et al., 1999; Ikeuchi et al., 1999), concern exists that some more important leakage of radionuclides from the dumped waste may occur. The question is where they might be transported by currents and dispersion, and especially after what time and in what concentrations they would reach the surface layers, where they might contaminate fish and other marine organisms. Therefore a research with measurements and modelling of the transport and dispersion of radionuclides was carried out at the International Atomic Energy Agency's Marine Environment Laboratory in Monaco.

A 3D mathematical model PCFLOW3D has been developed and specifically adapted to simulate the hydrodynamic circulation and the transport and dispersion of radioactive pollutants in lakes, coastal seas and oceans. The description of the model is given in section 2 .

\section{METHODS}

\subsection{Model description and simulation methodology}

The circulation in the very deep Japan Sea is clearly three-dimensional. For the simulation of the trans- 
port and dispersion of radioactive pollutants, an existing three-dimensional (3D) numerical model PCFLOW3D, developed at the University of Ljubljana, was adapted and applied. The model consists of three modules: the hydrodynamic module, the masstransport module and the sediment-transport module. The first two modules were used in this study.

\subsection{Hydrodynamic module}

As the applied model PCFLOW3D has already been described (Rajar, 1989; Rajar and Četina, 1997; Rajar et al., 1997), only its basic features are presented. It is $3 \mathrm{D}$, non-linear and baroclinic. Two momentum equa-

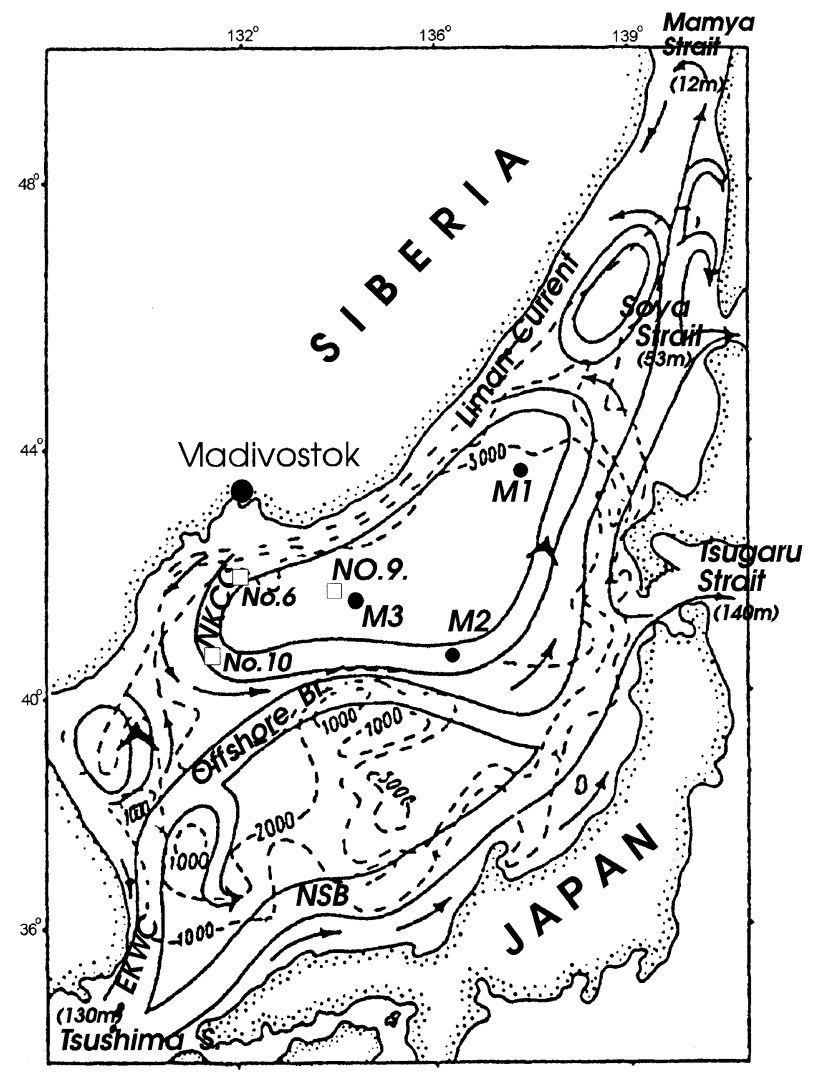

Figure 1. Topography of the Japan Sea with the observed pattern of surface currents (Adapted from Yoon, 1991b). EKWC: East Korean warm current; NKCC: North Korean cold current; NSB: Nearshore branch. Dumping sites No. 6, 9, and 10 are marked with squares. M1 to M3 are locations of current measurements of Takematsu et al., (1995, personal communication). tions are used, the third (in the vertical direction) is simplified to the hydrostatic equation. The Boussinesq approximation is used. The continuity equation and the equation for the surface boundary condition are applied additionally. Constant horizontal eddy viscosity is assumed and the one-equation turbulence model of Koutitas (Koutitas and O'Connor, 1980) is used to determine the vertical eddy viscosity. The influence of stratification on the value of eddy viscosity and diffusivity is taken into account as a function of the Richardson number (Rodi, 1980). The numerical solution is based on the implicit finite volume numerical method of Patankar (1980). The hybrid (combination of central and upwind) numerical scheme is applied.

The advection-diffusion equations for temperature and salinity are solved coupled with the above-mentioned equations. The equation of state determines the density, which is taken into account in the momentum equations in the next time step.

As described in section 5, the first results of the hydrodynamic simulations have shown specific disagreement with the observed surface and subsurface circulation (Rajar, 1997). Therefore, simulation of the topographic stress, also named topostress or Neptune effect, was included in the model. The phenomenon is described by Holloway (1992) and Eby and Holloway (1994) to be due to the interaction of eddies with bottom topography, which can exert large systematic forces on the mean circulation. A simple representation of topostress after Eby and Holloway (1994) is used. The calibration of the model and determination of the value of topostress length parameter $L$ for the Japan Sea is described in section five.

\subsection{Mass-transport module}

The advection-diffusion equation is solved in the mass transport sub-model. As the simulations had to be executed over several decades, the finite volume numerical scheme was considered not to be accurate enough regarding numerical diffusion. The Lagrangian-based particle tracking method was used (Šrca, 1992), which has no numerical diffusion in the classical sense, as it directly describes the particles' trajectories. As is described in section 6, the application of the method showed its very good characteristics. 
The PCFLOW3D model has already been applied to many studies of surface water quality problems. An adapted version of the model for the oil spill simulation is operational in Slovenia (Rajar et al., 1995). The bio-geo-chemical cycling of mercury, originating from a former mercury mine in Slovenia, has been studied both with 2D and 3D models (Širca et al., 1999; Rajar et al., 2000). The model has also been used in the international study on the impact of French underground nuclear tests on the environment, where simulation of the outflow of sediments and plutonium from the Mururoa lagoon was simulated for different weather conditions (Rajar, 1998).

\subsection{Simulation methodology}

Due to the requested very long simulation time (up to forty years), it was not feasible to do simulations in 'real time', i.e. to execute unsteady simulations over years, with all the forcing factors being time-dependent. The usual procedure is to do time-averaging. From the data bases (NOAA, 1994) the temperature and salinity fields are given for each annual season. Thus we have made hydrodynamic simulations for the four seasons of the year, with all the input data (T-S fields, winds, inflow/outflow currents) being averaged over each season. For each season simulations were run for a period of 60 to 90 days when a final, nearly steady state velocity field was obtained.

The four hydrodynamic velocity fields were computed in the following manner. To simulate the thermohaline forcing, which is the most important forcing factor (see section 3), there are two possible methodologies: (1) to simulate directly the atmospheric heating and cooling throughout the year and their influence on the water circulation (e.g. as in Zavatarelli and Mellor, 1995 for the Mediterranean Sea); this is called the prognostic mode, or (2) to use measured data of temperature and salinity distribution in the sea and to force the hydrodynamic circulation with it in the diagnostic mode.

For several reasons we decided to adopt the diagnostic mode, which has a much shorter computational time. As is well known, forcing of hydrodynamic simulations with T-S data, taken directly from measurements, usually causes computational instabilities. This is due to inaccuracies in measurements and/or incompatibility of the real phenomenon with the model physics. Some authors use such a procedure that they run the advection-diffusion equation for $\mathrm{T}$ and $\mathrm{S}$ with a damping coefficient so that the T-S fields are partly smoothed during the simulations (Seung and Yoon, 1995). We decided on another method: a slight smoothing of the T-S fields before the hydrodynamic computations. For the first three days, only the diffusion of $\mathrm{T}$ and $\mathrm{S}$ was run, while all the flow velocities remained zero. Numerical tests have shown that this caused a very slight, but sufficient smoothing of the T-S fields. After this initial time, the T-S fields remained fixed in time and hydrodynamic computations were run. With this procedure included, the hydrodynamic computations were executed without stability problems. This is partly due to the properties of the PCFLOW3D model, which was found in many practical applications to be very robust.

During the simulations it was proven that the basic features of the pollutant dispersion are simulated accurately enough (within the possible order of accuracy of the whole research) only with the winter and summer velocity fields. Therefore the computed hydrodynamic velocity fields for these two seasons were saved on files to be used in the mass-transport model for simulations of the transport and dispersion of radioactive pollutants.

\section{FORCING FACTORS OF THE JAPAN SEA CIRCULATION}

As the radioactive waste was deposited on the seabed, the bottom currents are the most important for their transport and dispersion. However, due to the great difficulty of taking measurements at the depth of 3000 to $4000 \mathrm{~m}$, there exist only a few measurements of the bottom circulation that could be used for the model calibration and verification. On the contrary, there are sufficient measurements and observations of the surface circulation. To enable comparison of the model results with the available surface circulation pattern the forcing factors which influence the surface circulation were also taken into account. The following forcing factors were analyzed (Rajar, 1995; Četina et al., 1996).

(1) Thermohaline forcing is caused mainly by the intensive cooling of the northern part of the Japan Sea in winter. The maximum temperature difference between the northern and the southern part of the Sea in winter can reach $14{ }^{\circ} \mathrm{C}$. The water density in the NE part of the sea is also increased by ice 
formation, which causes salt release. Some measurements with chemical and radioactive tracers have shown that this forcing is of primary importance (Watanabe et al., 1991; Tsunogai et al., 1993), and it was taken into account in the simulations.

(2) During winter, from October to March, the wind over the Sea is fairly steady and strong, blowing from NW. The wind speed varies between 6 and $10 \mathrm{~m} \mathrm{~s}^{-1}$. During the rest of the year the wind is relatively weak and of variable direction. The mean annual wind is close to $7 \mathrm{~m} \mathrm{~s}^{-1}$, NW direction. Its effect on the surface circulation is important (Kim and Yoon, 1996), and its influence on the bottom currents should also be tested. Therefore the winds were accounted for in the simulations.

(3) Inflow surface currents. The Japan Sea is relatively enclosed, and is connected to the adjacent seas through four straits (figure 1), of which the TsushimaKorea strait between Japan and Korea is the most important. It is about $130 \mathrm{~m}$ deep and $170 \mathrm{~km}$ wide. Tsugaru strait reaches $140 \mathrm{~m}$ deep and about $20 \mathrm{~km}$ wide, while the Soya strait is $53 \mathrm{~m}$ deep and $40 \mathrm{~km}$ wide, and the Mamya strait between Sakhalin and Asia is only $12 \mathrm{~m}$ deep and $6.7 \mathrm{~km}$ wide.

Figure 1 shows a schematic surface current chart as obtained by several measurements and observations (from Yoon, 1991b). The Tsushima inflow current, which enters through the Tsushima-Korea strait, brings an important discharge into the Japan Sea. The outflow is usually taken as $75 \%$ of the inflow discharge through the Tsugaru strait and $25 \%$ through the Soya strait (Yoon, 1991b; Holloway et al., 1995); this was also taken into account in the simulations. Isobe et al. (1994) have published data about extensive measurements of currents in the Tsushima-Korea strait. They have found, that the maximum inflow was $5.6 \mathrm{~Sv}\left(1 \mathrm{~Sv}=10^{6} \mathrm{~m}^{3} \mathrm{~s}^{-1}\right)$ in September, and was about $1 \mathrm{~Sv}$ in other months. However, this is a very warm current, which due to its lower density cannot sink and interfere with the cold deep and bottom waters.

All the authors describing the exchange of the Japan Sea deep waters agree that the deep and bottom waters are practically not affected by the Tsushima warm current; only the surface waters of the upper 150 to $200 \mathrm{~m}$ are exchanged (Tsunogai et al., 1993).

For this reason it is expected, that the influence of the surface currents on the bottom circulation is of the second order of magnitude only. But these currents were taken into account to enable the comparison of the simulated and measured surface circulation.

(4) Tidal currents. The tide is semi-diurnal in the Tsushima strait, but becomes mainly a diurnal type in most parts of the Japan Sea. Tidal range is small: the amplitude is only $0.2 \mathrm{~m}$ along most parts of the Japanese coast, while it varies from 0.4 to $0.5 \mathrm{~m}$ on the Siberian coast and is about $2 \mathrm{~m}$ in the Mamya strait. Tidal currents can be relatively strong in the Tsushima strait (Isobe et al., 1994) (up to approximately $0.5 \mathrm{~m} \mathrm{~s}^{-1}$ in both directions). However, inside the sea the velocities become small, mostly less than $10 \mathrm{~cm} \mathrm{~s}^{-1}$. As tidal residual currents, which are important for the mean circulation, are for one or two orders of magnitude smaller, tidal forcing was not accounted for in the simulations.

(5) It was determined that the river inflow and precipitation have a negligible influence on the circulation and were not taken into account in the simulations.

As a conclusion, the bottom currents in the Japan Sea are mainly influenced by thermohaline forcing and, to a small extent, by wind forcing, while the surface currents are influenced by thermohaline forcing, by wind forcing, and by inflow/outflow currents. These three forcing factors were taken into account in the research.

\section{SIMULATIONS}

\subsection{Basic data for the simulations}

\subsubsection{Topography and numerical grid}

The computational region extends from $127^{\circ} 15^{\prime}$ to $141^{\circ} 45^{\prime}$ East and from $34^{\circ} 45^{\prime}$ to $52^{\circ} 15^{\prime}$ North. It was divided into $60 \times 72$ control volumes. The space step $D x=15^{\prime}$ longitude (from approximately $17.0 \mathrm{~km}$ at the southern boundary, to $24.2 \mathrm{~km}$ at the northern boundary) and $D y=15^{\prime}$ latitude (approximately 27.8 $\mathrm{km})$. As the computational region extends over $17^{\circ} 30^{\prime}$ in the $\mathrm{N}-\mathrm{S}$ direction, the cartesian co-ordinate system was replaced by the polar co-ordinate system, which can relatively well approximate the actual spherical geographical system. The model also takes into account the variable Coriolis parameter. 
In the Z-direction (along the depth) the field was divided into 15 active layers. Their thickness is chosen smaller at the surface $(D z=10 \mathrm{~m})$, to take into account more accurately the thermal and salinity stratification and the influence of the wind stress, and the grid is again denser near the bottom $(D z=200 \mathrm{~m})$ to better simulate the dispersion of radioactive pollutants near the bottom. In between, the maximum thickness of some layers is $450 \mathrm{~m}$. A maximum depth of $3500 \mathrm{~m}$ was supposed in the simulations.

\subsubsection{Wind}

The data on the wind field over the Japan Sea were obtained from Hellermann and Rosenstein (1983), and Levitus (1982). In the first simulations, with only wind forcing taken into account, a mean annual wind of $7 \mathrm{~m} \mathrm{~s}^{-1}$ from NW was accounted for. In the second phase of the research, approximate mean seasonal winds were evaluated, together with the influence of seasonal temperature and salinity fields. Spatially uniform wind was taken into account in all the cases. The values used in the simulations are presented in table $I$.

\subsubsection{Temperature and salinity}

The T-S data were taken from the World Atlas (NOAA, 1994). Figure 2 presents temperature distribution in the surface layer for winter conditions.

\subsubsection{Inflow/outflow surface currents}

Isobe et al. (1994) describe extensive current measurements in the Tsushima-Korea strait. From this and some other papers (Yoon, 1991a) the data on the inflow currents, presented in table I, were evaluated. According to Isobe et al. (1994), the inflow discharge is only through the western part of the strait. The logarithmic law for the distribution of the velocity along the depth was taken into account, so that the velocities in the bottom control volumes are about $35 \%$ of the surface values.

\subsubsection{Time step}

In the hydrodynamic part of the simulation, the time step was limited to $D t=180 \mathrm{~s}$ due to numerical stability. In the mass-transport sub-model (simulations of dispersion of radioactive pollutants by the particle tracking method), the value of $D t=0.5$ day was used.
Table I. Data on seasonal wind and on inflow discharge through the Tsushima strait.

\begin{tabular}{lllll}
\hline & Winter & Spring & Summer & Autumn \\
\hline Wind ( $\left.\mathrm{m} \mathrm{s}^{-1}\right)$ & $9.5 \mathrm{NW}$ & 0.0 & 0.0 & $8.4 \mathrm{NW}$ \\
Inflow (Sv) & 1.1 & 1.0 & 2.2 & 1.2 \\
\hline
\end{tabular}

\subsubsection{Eddy viscosity and diffusivity}

For the horizontal eddy viscosity the values from $N h=500$ to $5000 \mathrm{~m}^{2} \mathrm{~s}^{-1}$ were tested. Sensitivity to this parameter is very small, higher values give

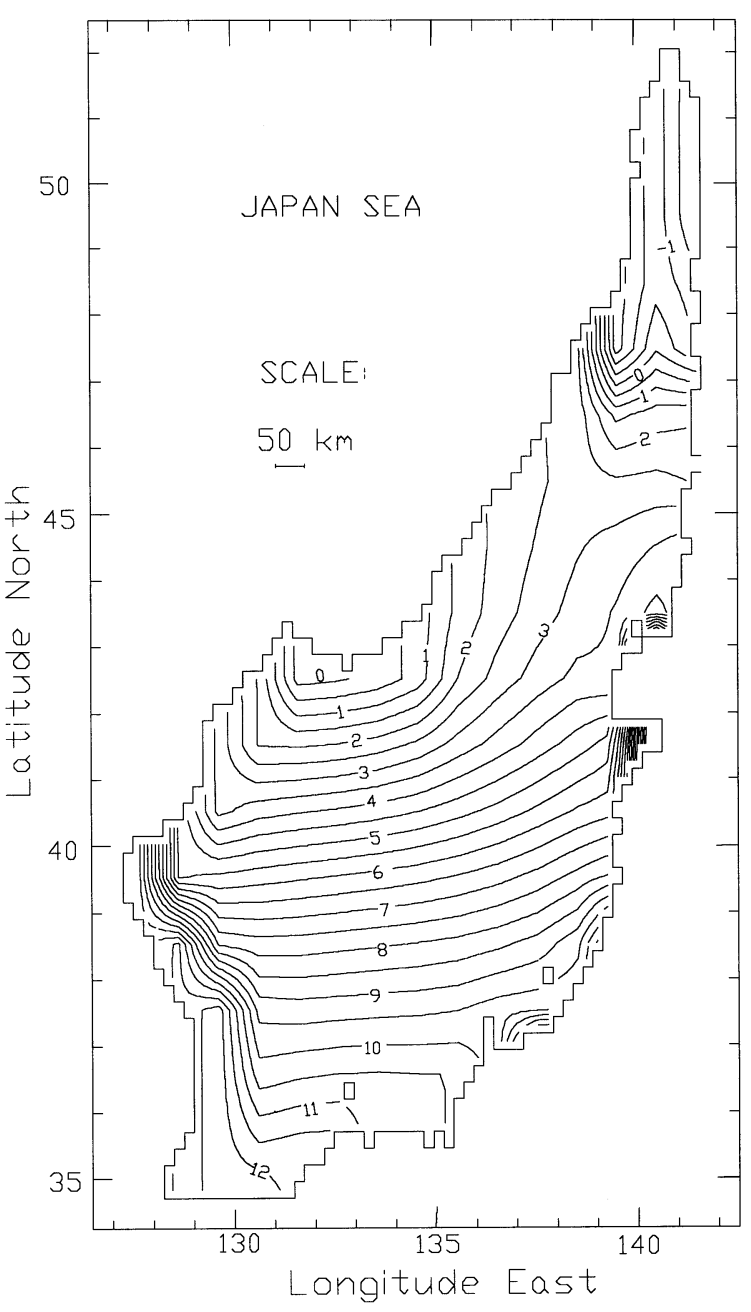

Figure 2. Temperature distribution in the surface layer - winter conditions (data from NOAA, 1994). 

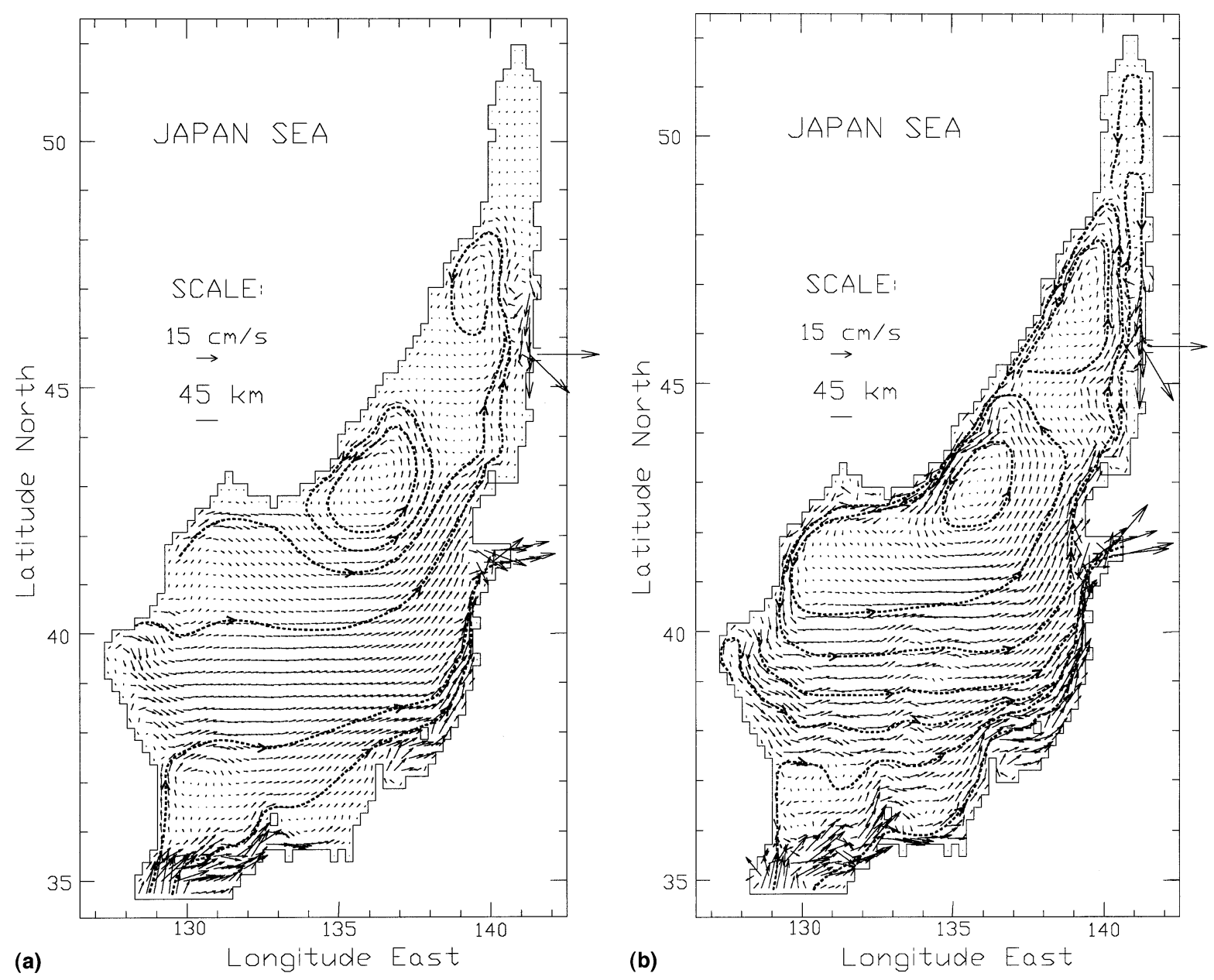

Figure 3. Simulated velocities in the surface layer ( 0 to $10 \mathrm{~m}$ ) for summer conditions (no wind) with main trajectory lines. (a) Without topostress; (b) with topostress.

slightly smoother velocity fields. The value of $N h=$ $1500 \mathrm{~m}^{2} \mathrm{~s}^{-1}$ has been used in the final computations, and the same value for horizontal diffusivity $D h$. For determination of the vertical eddy viscosity $N v$, the one equation turbulence model of Koutitas and O'Connor (1980) is included in the PCFLOW3D model (see Section 2.2). However, for the very deep Japan Sea the resulting values of $N v$ are of the order of $10^{-2}$ to $10^{-1} \mathrm{~m}^{2} \mathrm{~s}^{-1}$, which are very high values, compared to those of several other authors. The difference is explicable by the fact, that in Koutitas' model it is supposed that the main forcing factor is wind, which is not the case in this research. Holloway et al. (1995) as well as Seung and Yoon (1995) have determined the vertical eddy viscosity to be $N v=10^{-4}$ $\mathrm{m}^{2} \mathrm{~s}^{-1}$. This value was used in the final simulations. The influence of stratification on $N v$ and $D v$, expressed by Richardson's number, was taken into account in all the simulations.

For long term simulations of the transport-dispersion of radioactive pollutants (by the particle tracking method) the proper value of the vertical diffusivity $D v$ is very essential. As there was no possibility of calibration, $D v$ was determined by a thorough study of available literature. Several authors have obtained similar values: Gamo and Horibe (1983) determined the value of $D v$ to be $410^{-5} \mathrm{~m}^{2} \mathrm{~s}^{-1}$ which was roughly confirmed by measurements with chemical and radioactive tracers. Seung and Yoon (1995) have found a similar value of $N v=5 \quad 10^{-5} \mathrm{~m}^{2} \mathrm{~s}^{-1}$. The 
value of $D v=410^{-5} \mathrm{~m}^{2} \mathrm{~s}^{-1}$ was finally used in our simulations.

\subsection{Simulations with wind forcing only}

To distinguish the relative importance of the two main forcing factors, i.e. the thermohaline forcing and the wind forcing, some simulations with wind forcing only were executed first. The resulting current velocities in the bottom layers would range from 0.5 to $3 \mathrm{~mm} \mathrm{~s}^{-1}$, which, as expected, is an order of magnitude smaller than the velocities resulting from thermohaline forcing.

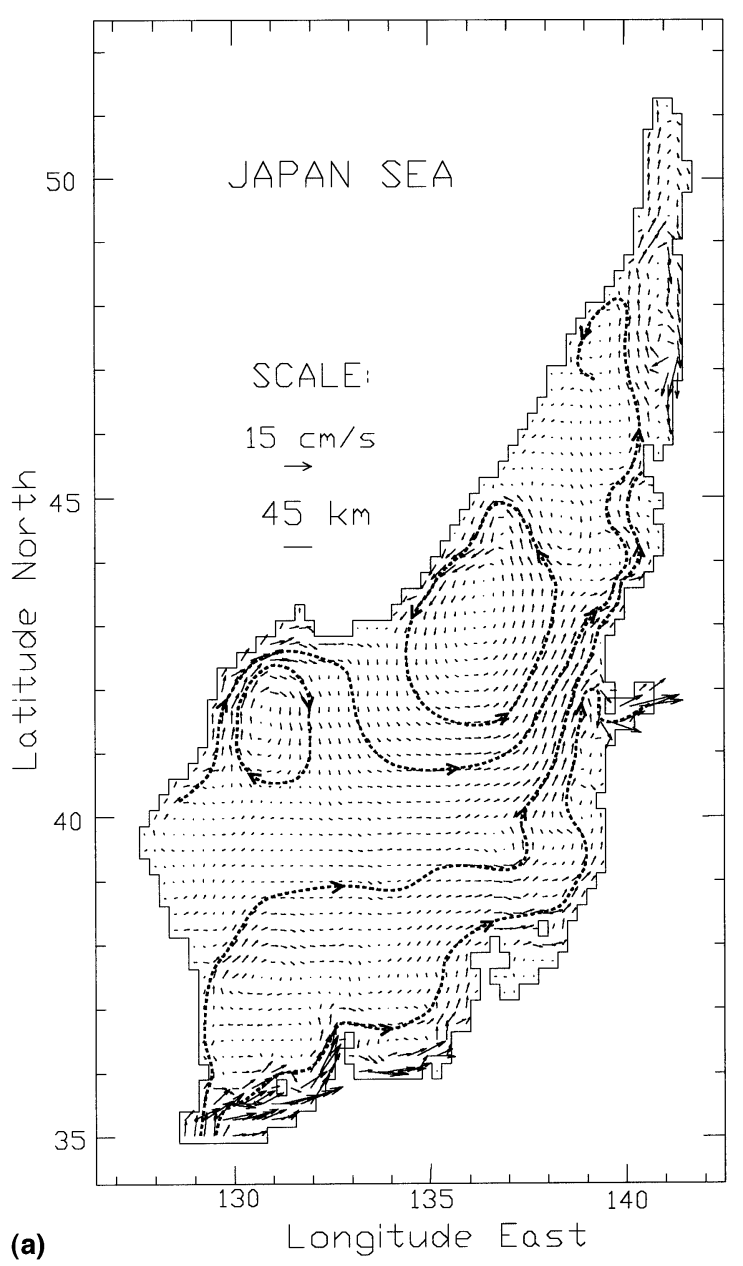

\subsection{Simulations with wind, thermohaline forcing and inflow/outflow currents}

As already stated, the final simulations of the transport of radioactive pollutants with the mass-transport module were executed with only winter and summer velocity fields due to little detailed input data, and due to the fact that the circulation in all four seasons have common basic features. Hence the simulation of winter and summer circulation is described.

Simulated velocity fields are presented in figures 3 and 4 for the surface and near-surface layers, in figure 5 for layer 9 (depth 500-800 m) and in figures 6 and 7 for the deep and bottom layers. Comparison with the observed currents is described in the next section.

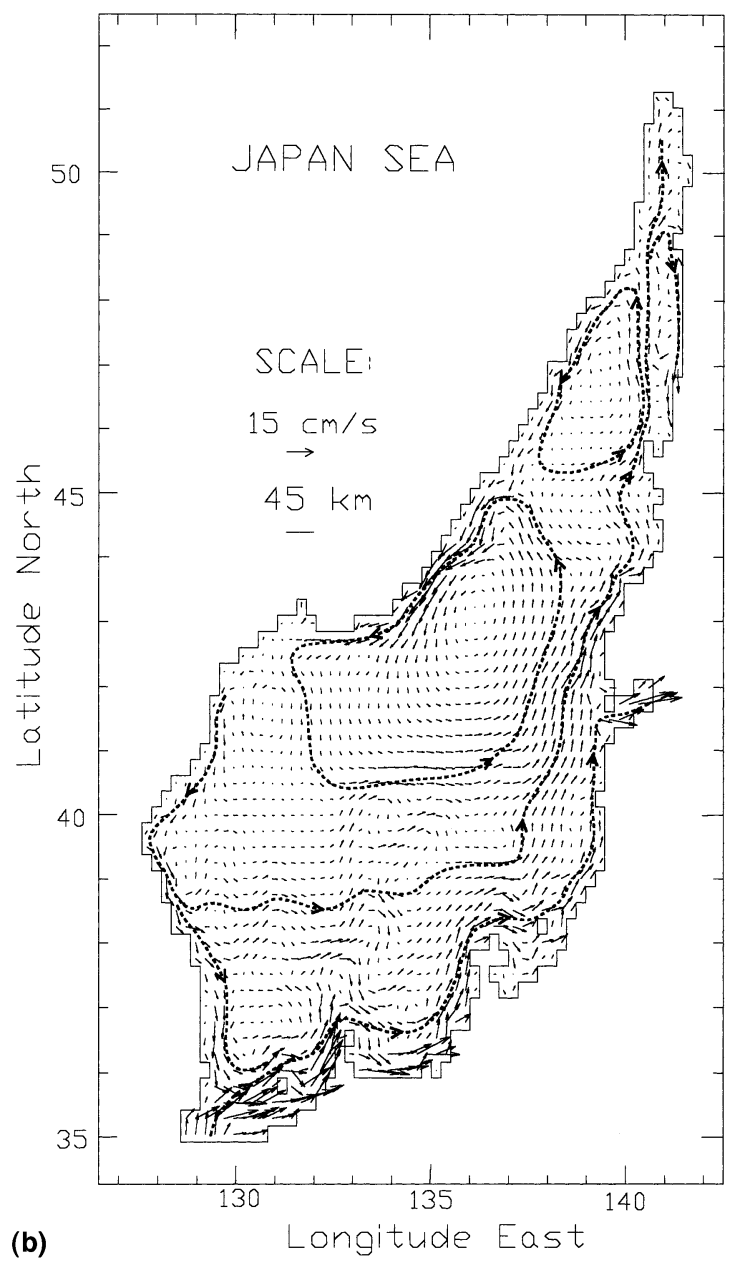

(b)

. (a) No topostress, Figure 4. Simulated velocities with
$L=0$; (b) $L=4 \mathrm{~km}$; (c) $L=6 \mathrm{~km}$. 


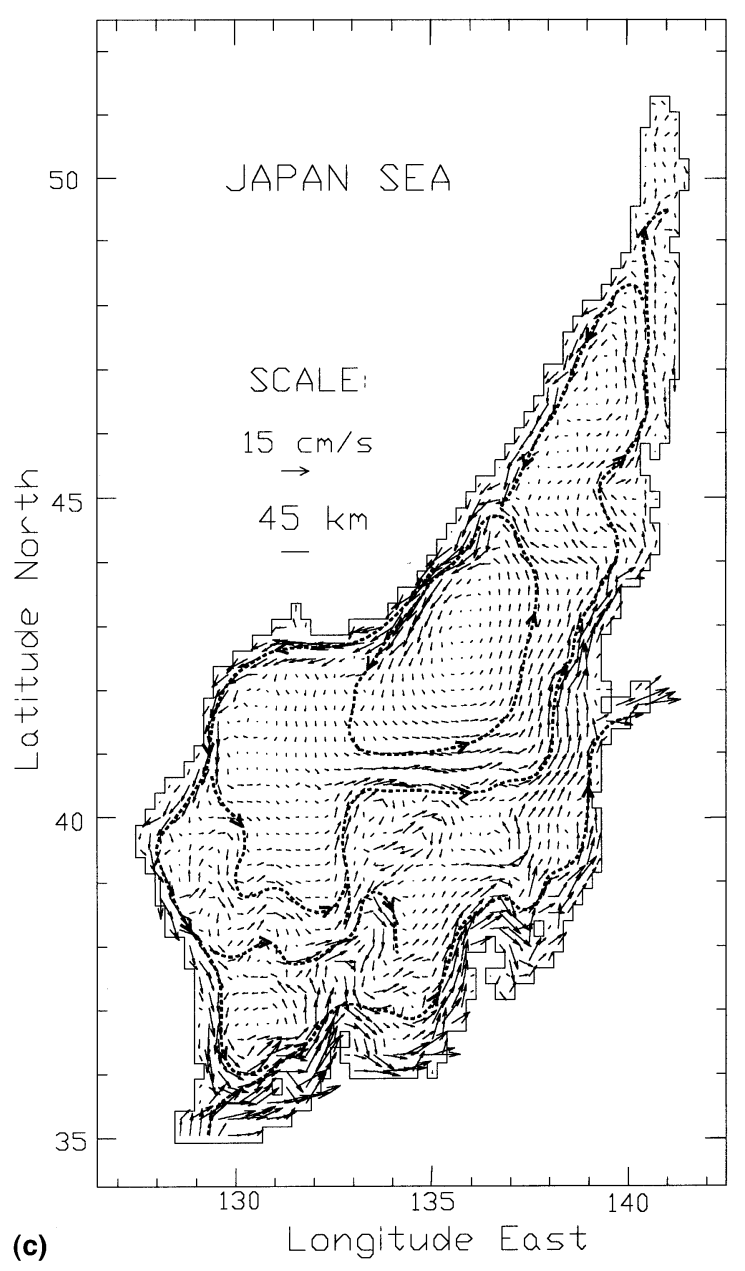

Fig. 4. (Continued)

\section{CALIBRATION AND VERIFICATION}

\subsection{Surface currents}

Considerable research on measurements and modelling of the Japan Sea surface circulation has already been carried out (Holloway, 1992; Lie Heung-Jae and Byun Sang-Kyung, 1985; Lie Heung-Jae et al., 1989; Seung and Yoon, 1995; Yoon, 1995, 1991a). Comparison of simulated surface currents with the relatively well measured and described circulation offered a good possibility of confirming the general validity of the mathematical model.

The best published scheme of measured surface currents is presented in figure 1 (from Yoon, 1991b). As the annual season is not specified, it should represent the average annual circulation.

This circulation was first compared with the simulated pattern in figure $3 a$, for summer conditions. The summer season was initially chosen here for comparison, because strong winds in autumn and winter deflect the velocity in the very surface layer from the directions of the general surface currents, which extend down to a depth of about $150 \mathrm{~m}$.

Mainly the computed circulation (figure $3 a$ ) is in very good agreement with the observed one (figure 1). The simulation presents well the nearshore branch, the offshore branch, and both cyclonic gyres with the Liman and the North Korean Cold Current (NKCC). The East Korean Warm Current (EKWC) is also simulated, although a little too weakly. Even the detail of a separation from EKWC, forming a southward flowing branch, is reproduced. There is only one detail that is not in agreement with the observations: the southern part of the North Korean Cold Current should reach further toward the west, south of Vladivostok, but at that location the simulation shows an anti-cyclonic gyre. In figure $4 a$, showing simulated winter circulation, this non-realistic gyre is even stronger.

It is interesting that most modellers find this same disagreement with the observations. This is called the 'overshooting of the East Korean Warm Current'. Following Holloway et al. (1995) we have included the simulation of the topographic stress (or Netune effect) in our model, as it seems that this eliminates, or at least diminishes the overshooting, and possibly also improves some other details of the simulated circulation.

The first problem was to determine the value of the calibration parameter $L$, the topostress length parameter. For this sea Holloway et al. (1995) have determined this value to be $L=6 \mathrm{~km}$, but in our simulations this value seems to be too high. Figures $4 a, b$ and $c$ show comparison of the simulated circulation with $L=0,4$ and $6 \mathrm{~km}$ respectively. For the computational layer thirteen (depth from 50 to 100 $\mathrm{m}$ ), the comparison is made for winter conditions, as the measurements are evaluated over the layer which extends from the surface to about $150 \mathrm{~m}$ depth, and the velocities in the computed thin surface layer (10 m) show too concentrated effect of the wind stress. It 
can be seen (figure 4c) that the value of $L=6 \mathrm{~km}$ causes too strong cyclonic circulation all over the basin. However, both winter and summer circulation simulated with $L=4 \mathrm{~km}$ (figure $4 b$ and $3 b$ ) indicate visibly better agreement with the observed circulation than the results without topostress. Holloway (personal communication) explains that the difference in the value of topographic length $L(6 \mathrm{~km}$ in his study, $4 \mathrm{~km}$ in this research) is possible, as it also depends on the model numerics, grid resolution, viscosity and other parameters.

Several features are improved with the topostress included: the anti-cyclonic gyre off Vladivostok is eliminated (in summer it is replaced by a realistic cyclonic gyre). Both in winter and summer conditions

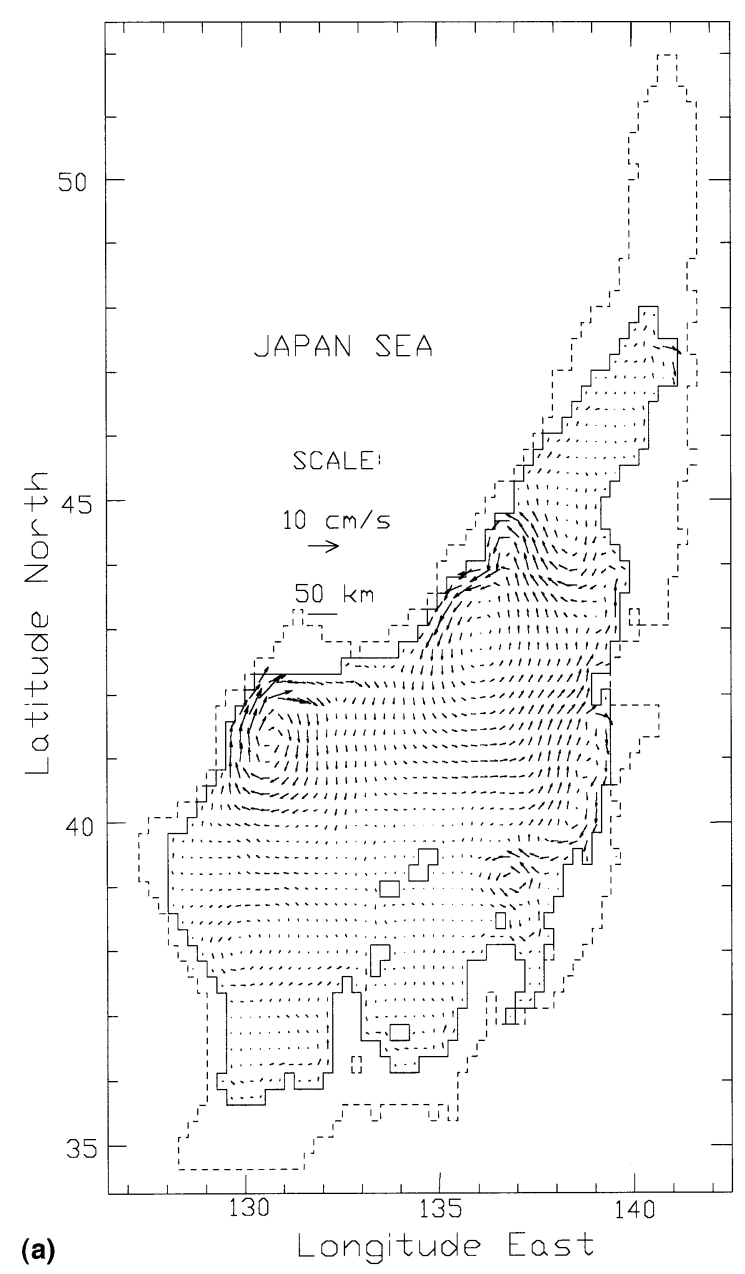

the two cyclonic gyres, the larger in the Japan Basin (containing the NKCC in the west part), and the smaller northern gyre, are enhanced, which agrees better with the observations.

Both in summer and in winter conditions the nearshore branch is enhanced, which seems to be nearer to reality (Holloway et al., 1995).

\subsection{Subsurface circulation}

Even stronger support for the topostress theory is obtained when comparing the simulated results with measurements in the subsurface layers, at depths of about 500 to $1000 \mathrm{~m}$. Several authors (Holloway et

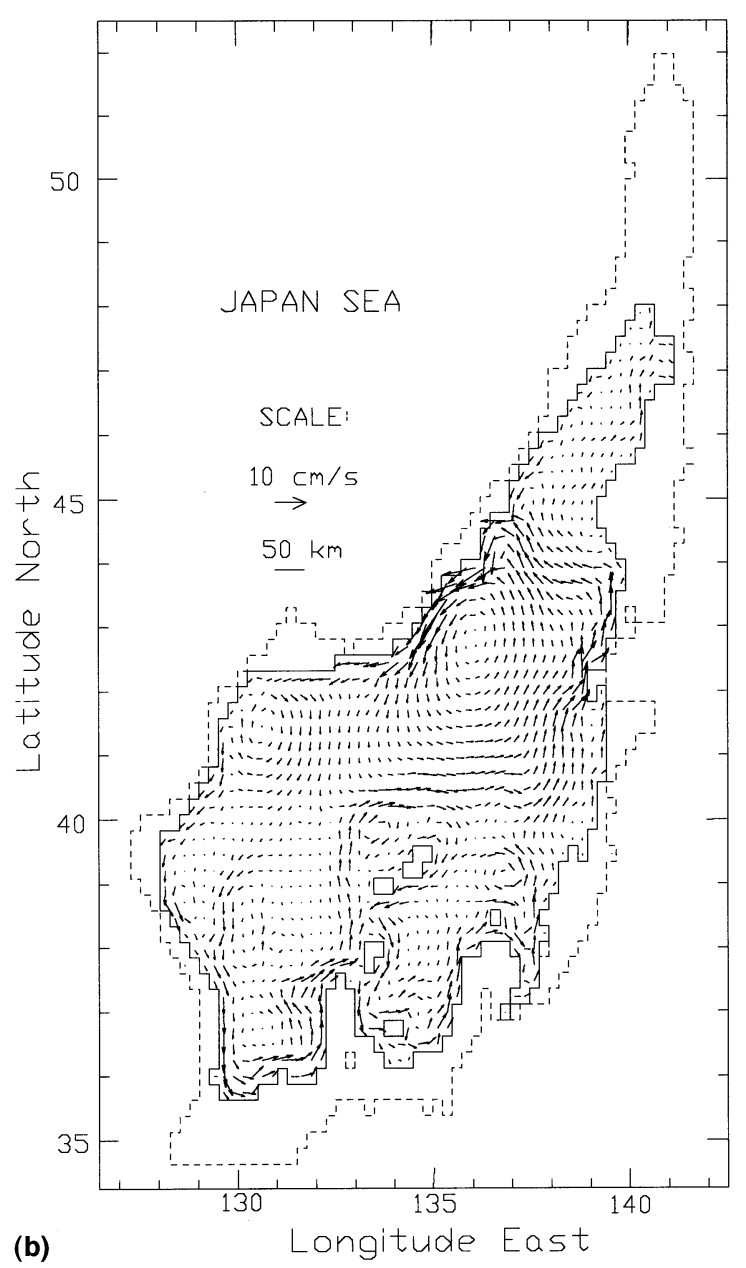

Figure 5. Simulated hydrodynamic circulation in layer 9 (500 to $800 \mathrm{~m}$ ). (a) Winter, $\mathrm{L}=0$; (b) winter, $\mathrm{L}=4 \mathrm{~km}$; (c) summer, L=0; (d) summer, $\mathrm{L}=4 \mathrm{~km}$. 


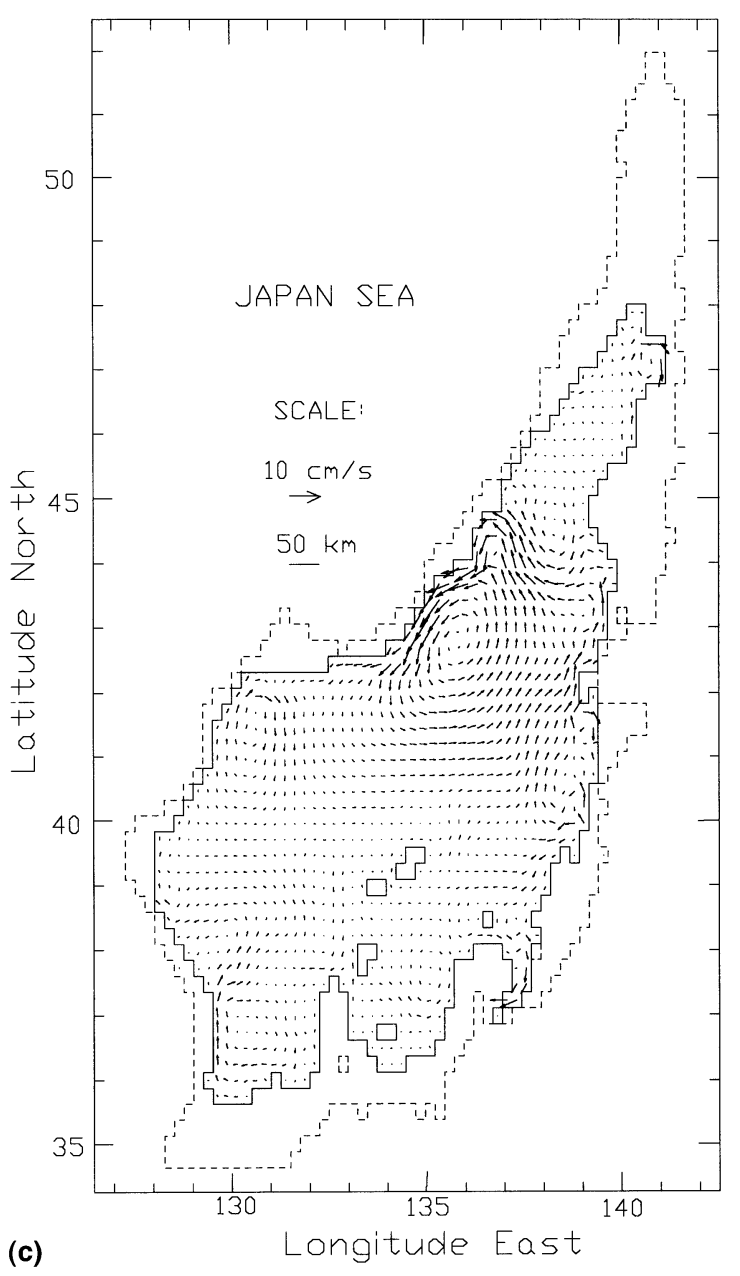

Fig. 5. (Continued)

al., 1995) describe relatively strong south- to southeastward currents along the East Korean coast, under the EKWC. The results of the present research are presented for layer 9 at $500-800 \mathrm{~m}$ depth in figures $5 a$ and $b$ for winter conditions and in $5 c$ and $5 d$ for summer conditions. When topostress is not taken into account, the simulations show no southward flow along the Korean coast in winter, and there is even a northward flow in summer. On the contrary, with topostress taken into account, both in the winter and summer situation there is a southward current along the coast down to the Tsushima sill, with velocities of approximately $4 \mathrm{~cm} \mathrm{~s}^{-1}$.

Another detail confirms the topostress theory. Looking at the results of the same two authors (Holloway et al., 1995; Seung and Yoon, 1995), the flow south of

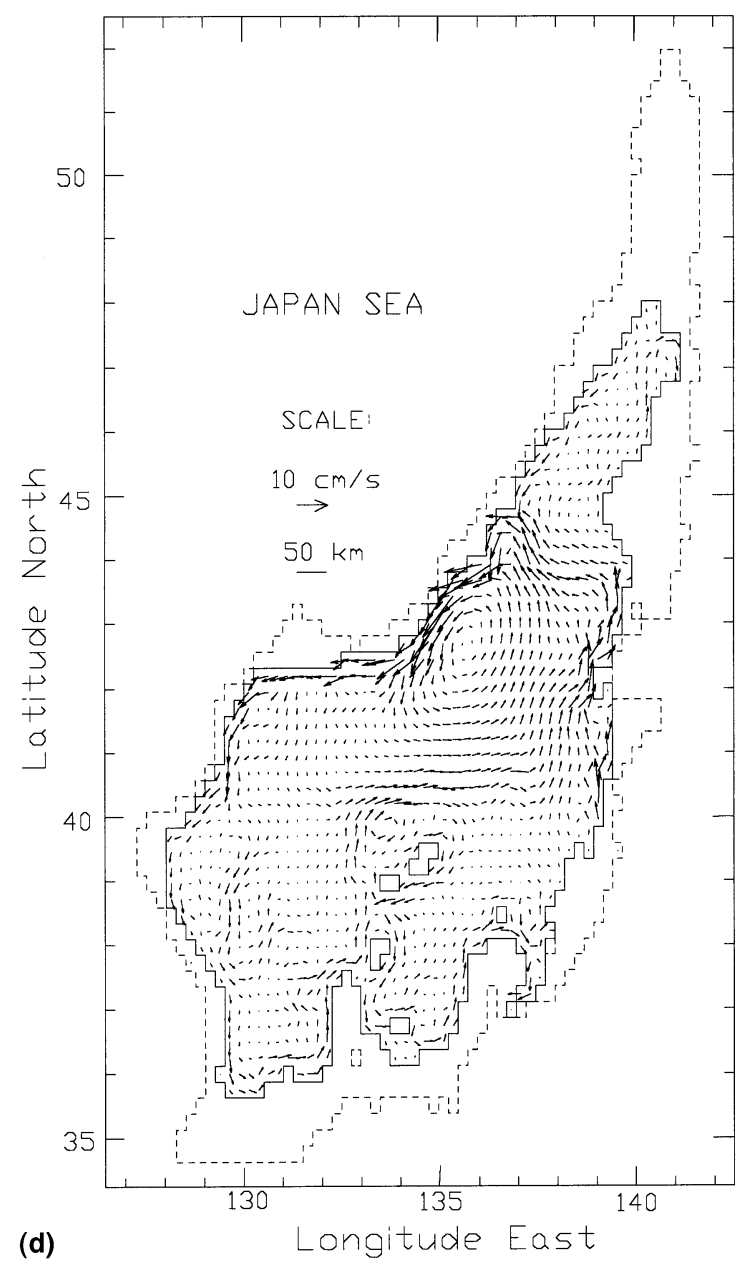

Vladivostok is clearly west, within a cyclonic gyre. Our simulations without topostress show a strong anti-cyclonic gyre in winter and a weak gyre of the same direction in summer. Simulations with topostress show much better agreement: a stronger cyclonic gyre in summer and a neutralization of the anti-cyclonic gyre in winter.

\subsection{Bottom currents}

As it has been described, the applied model was relatively well verified for the surface and subsurface circulation. However, regarding the final goal of the research, the proper simulation of the bottom circulation was of utmost importance. Figure 6 shows the 
simulated circulation in layer 5 (2 100 to $2550 \mathrm{~m}$ ) and figure 7 the bottom circulation in layer 7 (3 300 to $3500 \mathrm{~m})$.

The only available direct measurements of bottom currents were carried out by Takematsu et al. in 1995 using current meters, attached to three moorings, at the depths of $1000,2000,2500$ and $3000 \mathrm{~m}$. Their locations are marked in figure 1 with M1 to M3. The duration of the recording was 11 months and the data sampling interval was $1 \mathrm{~h}$ (M. Takematsu, personnal communication).

Comparison of the simulated and measured velocities can only be qualitative, as the simulations were executed with forcing parameters, averaged over each season, while the measured velocities were obtained

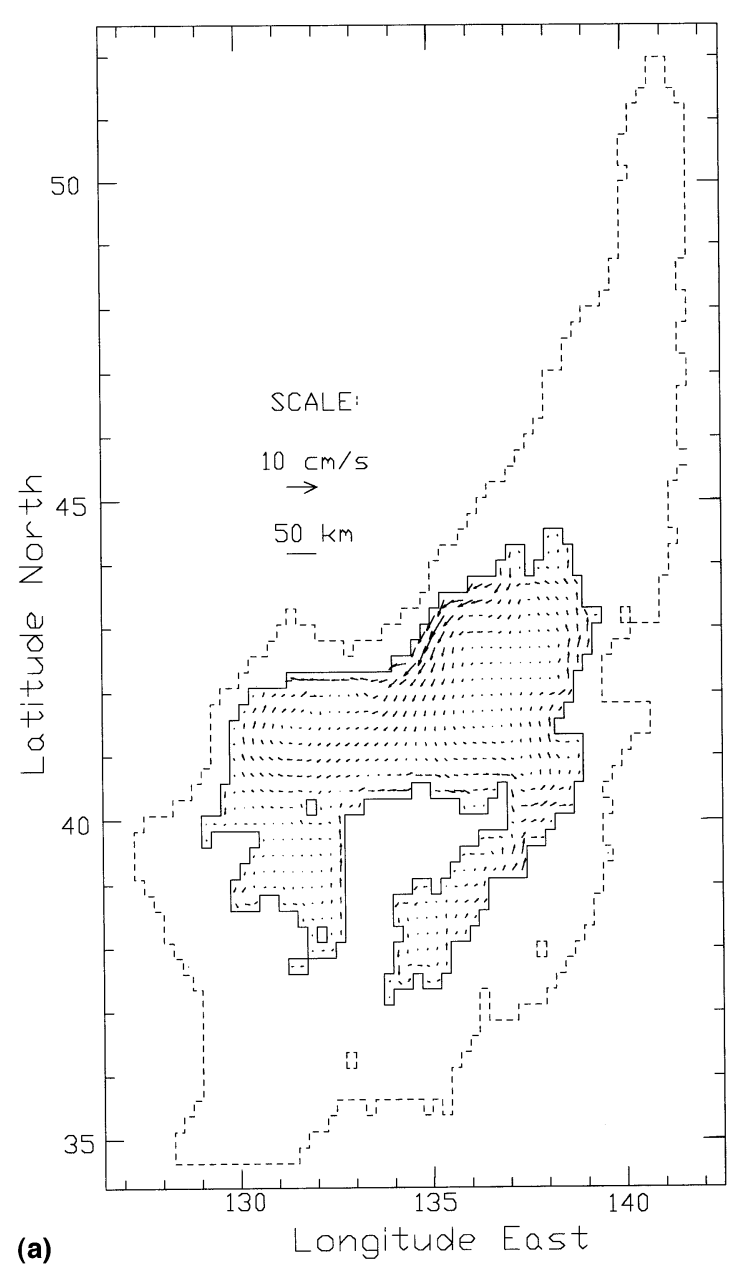

from one specific measurement (August 93 to July 94). The comparison was also difficult because the measured velocities vary very much during each season, both in direction and in magnitude. We were only able to compare the order of magnitude of the velocities. Maximum measured velocities in the bottom layers, even at the depth of $3000 \mathrm{~m}$, are surprisingly high, up to $10 \mathrm{~cm} \mathrm{~s}^{-1}$, mainly in spring. It is interesting that the simulations have also shown maximum velocities up to $9 \mathrm{~cm} \mathrm{~s}^{-1}$ in winter and spring conditions (figure 7), while in other seasons they are up to $4 \mathrm{~cm} \mathrm{~s}^{-1}$.

Comparison of the measurements with the model results for two simulations, with and without topostress, have shown no significant difference.

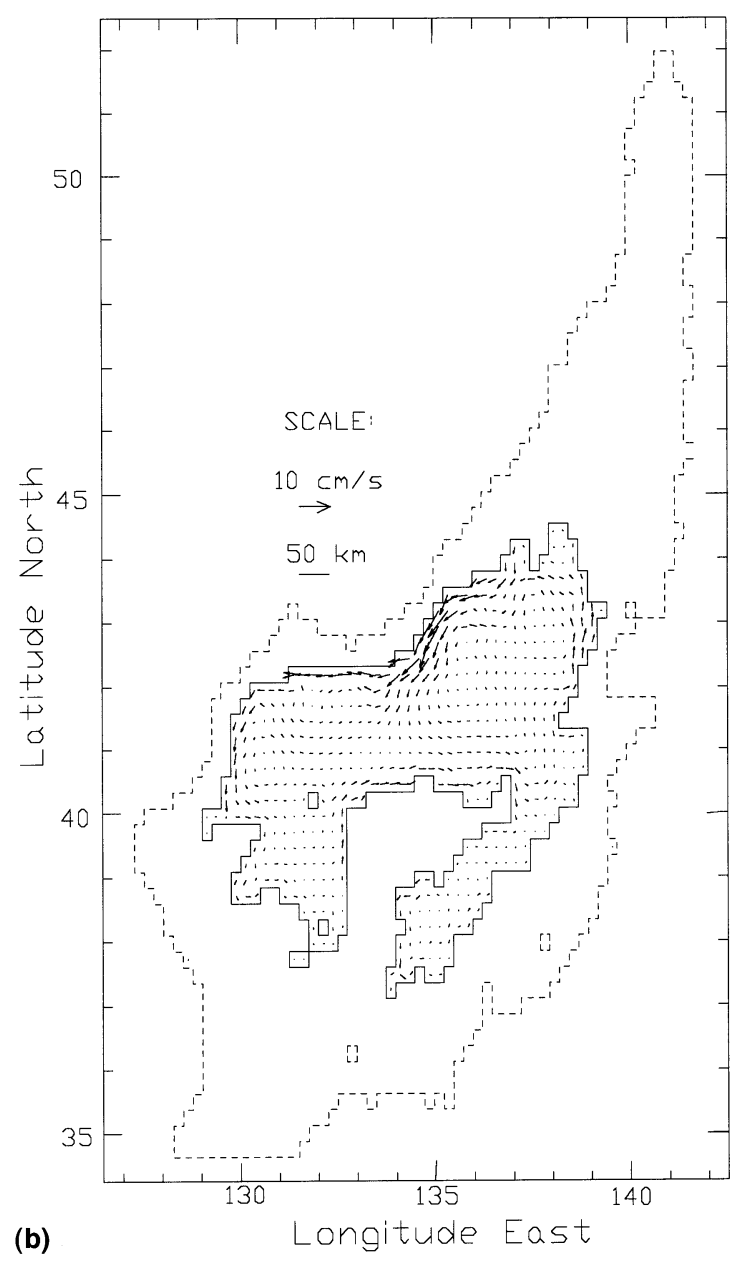

Figure 6. Simulated hydrodynamic circulation (with topostress $L=4 \mathrm{~km}$ ) in layer 5 (2 100 to $2550 \mathrm{~m}$ ): (a) winter; (b) summer. 


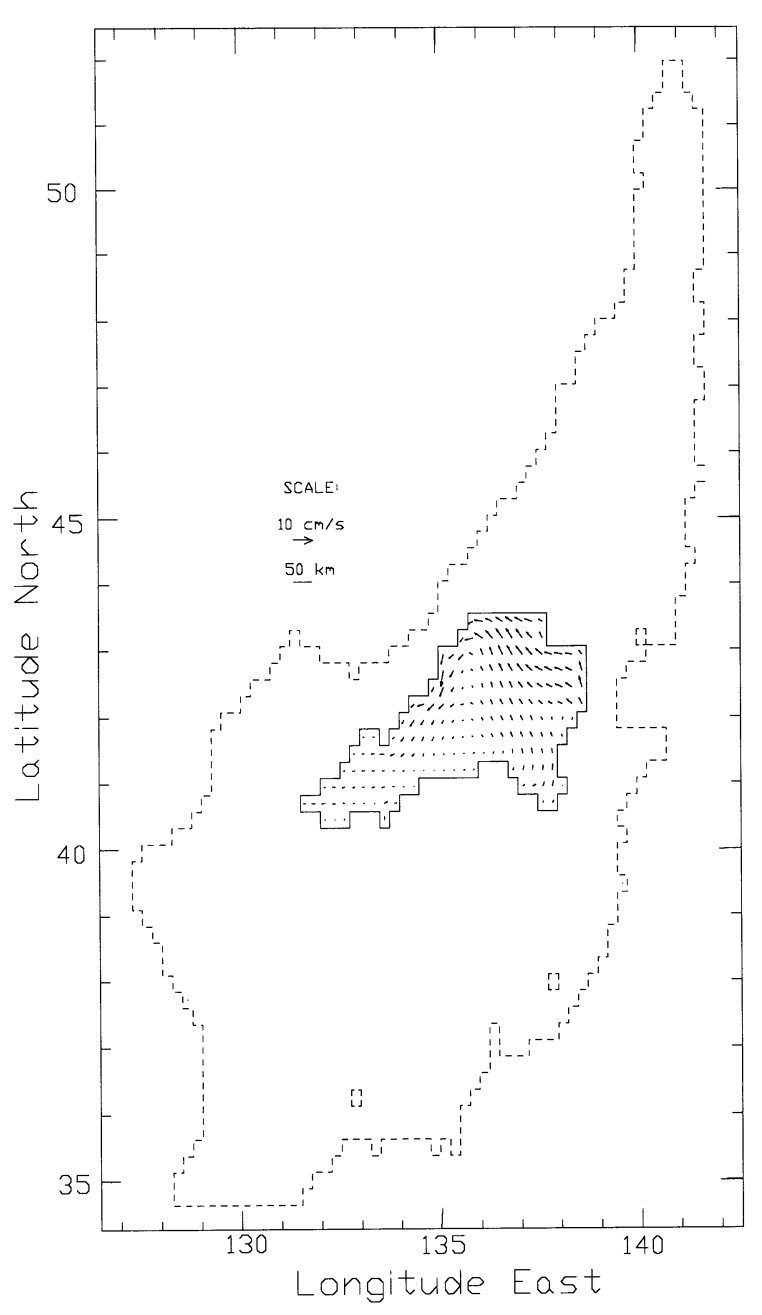

Figure 7. Simulated hydrodynamic circulation (with topostress $L=4 \mathrm{~km}$ ) in the bottom layer 2 (3300 to $3500 \mathrm{~m}$ )-winter conditions.

\section{RESULTS: TRANSPORT-DISPERSION OF RADIOACTIVE POLLUTANTS}

\subsection{Data}

On the basis of the computed winter and summer hydrodynamic circulation, the transport and dispersion of radioactive pollutants was simulated by the mass-transport sub-model, using the particle tracking method. As previously mentioned, the simulation scenario was the release of $1 \mathrm{TBq}$ continuously for 90 days at the dumping location 9 (see figure 1), with no decay taken into account. Fifty particles were re- leased at each time step of 0.5 day, which resulted in a total number of 9000 particles in ninety days.

\subsection{Results and comments}

Figure $8 a$ shows the dispersion of particles, after five years of simulation in layer 5 (depth 2100 to 2550 $\mathrm{m})$. For comparison, figure $8 b$ shows the result of simulation without topostress $(L=0)$. The difference between both results is important. The hydrodynamic simulations have shown that the horizontal circulation is much stronger with $L=4 \mathrm{~km}$ than with $L=0$. The effect of this phenomenon can be seen in figures $8 a$ and $b$ : with topostress the transport-dispersion of particles is mainly along the bottom contours, with cyclonic circulation, and is much stronger than without topostress.

Figures $9 \mathrm{a}$ and $b$ show the location of particles in layer 12 , which is the most interesting from the point of view of possible contamination of fish, as it is located at a depth of 100 to $180 \mathrm{~m}$, the deepest layer where fishing is still carried out. Results are shown after five years, and then after thirty years of simulation when approximately the maximum concentrations are attained. It can be seen that the activity is dispersed almost all over the Japan sea in this nearsurface layer, but the strongest contamination would be in the region north of the central part. The maximum values of calculated concentration, attained at some locations in this layer, is of the order $10^{-3} \mathrm{~Bq} \mathrm{~m}^{-3}$. Figure $9 c$ shows the situation in the uppermost layer, $10 \mathrm{~m}$ thick. Even after thirty years there are only a few particles in this layer, but as indicated in the figure, a small amount of particles have been washed out through the Tsugaru and the Soya straits. The concentration of radionuclides at the sea bottom was not studied in detail, as it was not demanded by the research plan.

More information about the temporal changes in concentration is given in figure 10, curve $c$, where the time development of the number of particles and of the average concentration in the upper part of the Sea, above the depth of $180 \mathrm{~m}$, is shown. The first particles (causing very small concentrations) reach the surface layers after about 3 years already. For the assumed input data, the highest average concentration in the upper $180 \mathrm{~m}$ is about $610^{-5} \mathrm{~Bq} \mathrm{~m}^{-3}$ and it is attained 30 years after the spill of the radioactive waste at the bottom. 

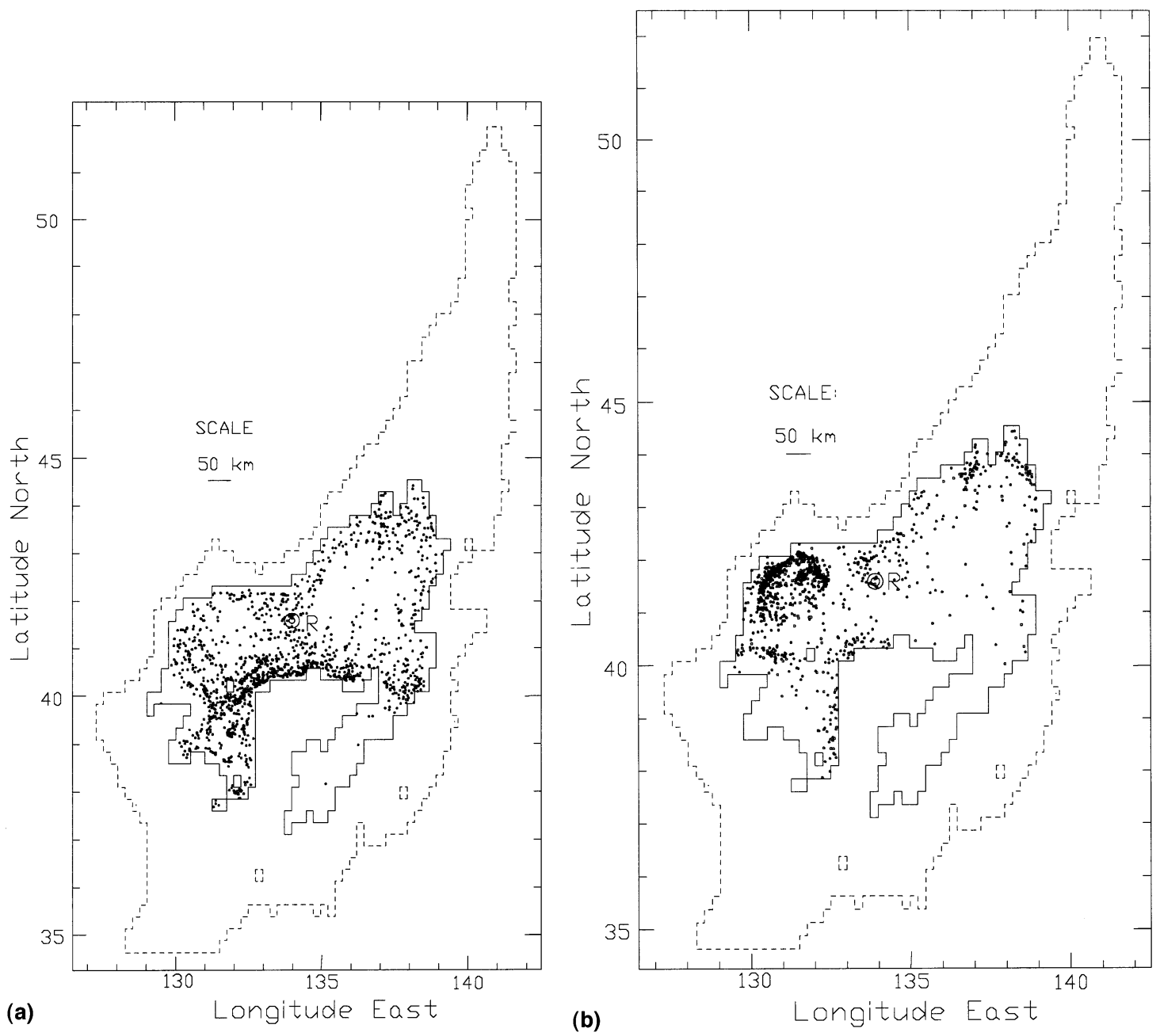

SCALE:

$50 \mathrm{~km}$

$400 \mathrm{~m}$

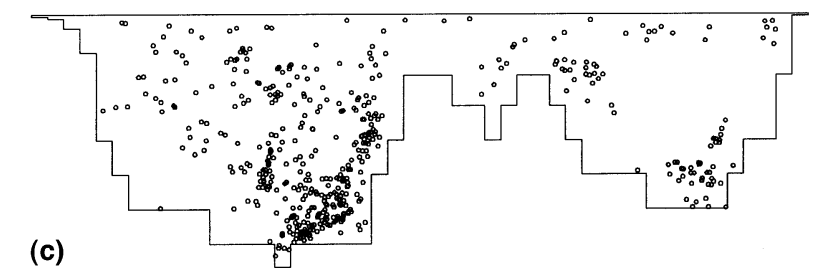

Figure 8. Simulated transport-dispersion of particles, 5 years after the beginning of the release of 9000 particles from dumping site 9 (at $3500 \mathrm{~m}$ depth). Each particle represents $111 \mathrm{MBq}$. Winter and summer hydrodynamic fields are exchanged every $6 \mathrm{months}$. R - location of the release (at the bottom). (a) Layer 5 (depth $2100-2550 \mathrm{~m}$ ), with topostress, $L=4 \mathrm{~km}$; (b) same as (a), with $L=0$; (c) vertical cross section $\mathrm{E}-\mathrm{W}$, at $40^{\circ} 7.5^{\prime}$ North, $L=4 \mathrm{~km}$. 
For comparison, figure 10, curve $d$ also shows the time development of the concentration for the simulations without topostress. The maximum concentration, also attained after thirty years, is only about $3.710^{-5} \mathrm{~Bq} \mathrm{~m}$ m $^{-3}$, which is almost $40 \%$ smaller. Figure 11 is an attempt to present the transport-dispersion of particles in 3 dimensions.

In figure 12, a 3D view of the trajectory of one particle is presented. The numbers only mark the direction of the particle's movement. The positions of the particles (small circles) are marked at each time step of $D t=0.5$ days.

In the upper layer of the Japan sea (above $180 \mathrm{~m}$ depth) even the maximum concentrations caused by the release of $1 \mathrm{TBq}$ of ${ }^{137} \mathrm{Cs}$ from the dumping

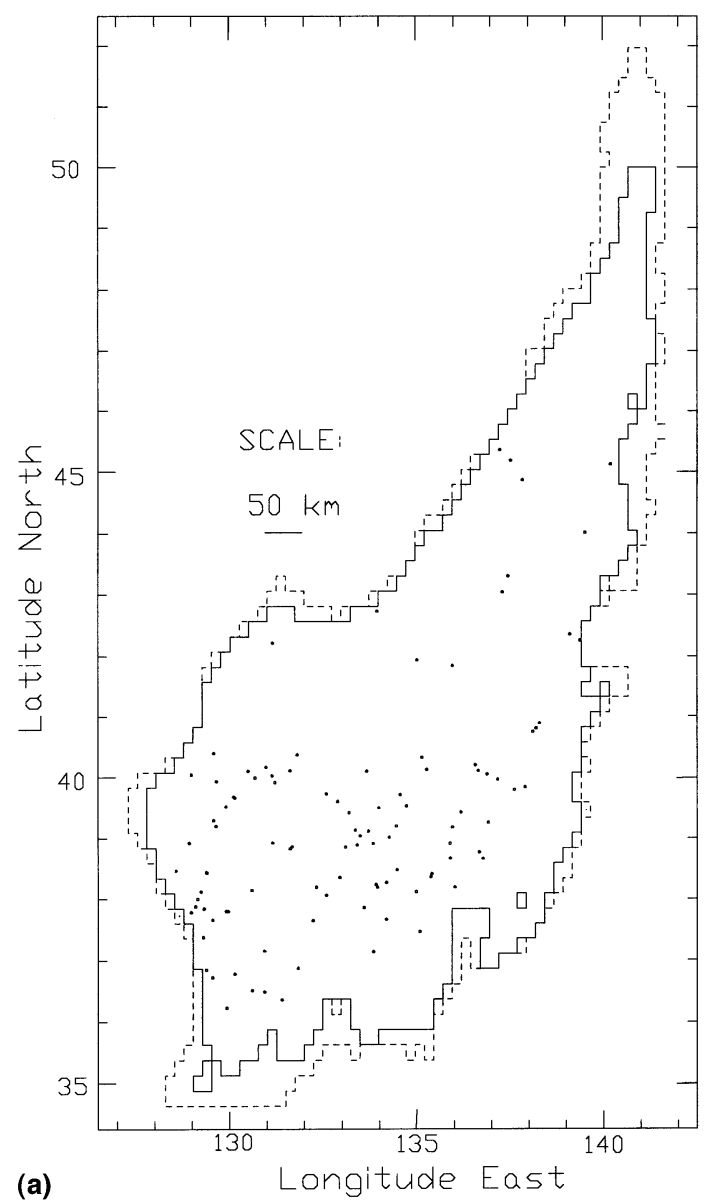

site are locally at least two orders of magnitude smaller than the measured present background values which are about $3 \mathrm{~Bq} \mathrm{~m}^{-3}$ (Hirose et al., 1999; Ikeuchi et al., 1999). This background is due to global fallout from atmospheric nuclear weapons tests mainly carried out in the sixties. The present surface ${ }^{90} \mathrm{Sr}$ concentrations measured in the Japan Sea/East Sea are about $2 \mathrm{~Bq} \mathrm{~m}^{-3}$. The bottom ${ }^{90} \mathrm{Sr}$ and ${ }^{137} \mathrm{Cs}$ concentrations measured at the dumping sites were from 0.4 to $0.7 \mathrm{~Bq} \mathrm{~m}^{-3}$ and from 0.8 to 1.6 $\mathrm{Bq} \mathrm{m}^{-3}$, respectively (depending on water depth). As previously mentioned, contributions from other radionuclides could be neglected either because of lower concentrations in wastes, shorter half lives, or their removal from the water column by scavenging processes.

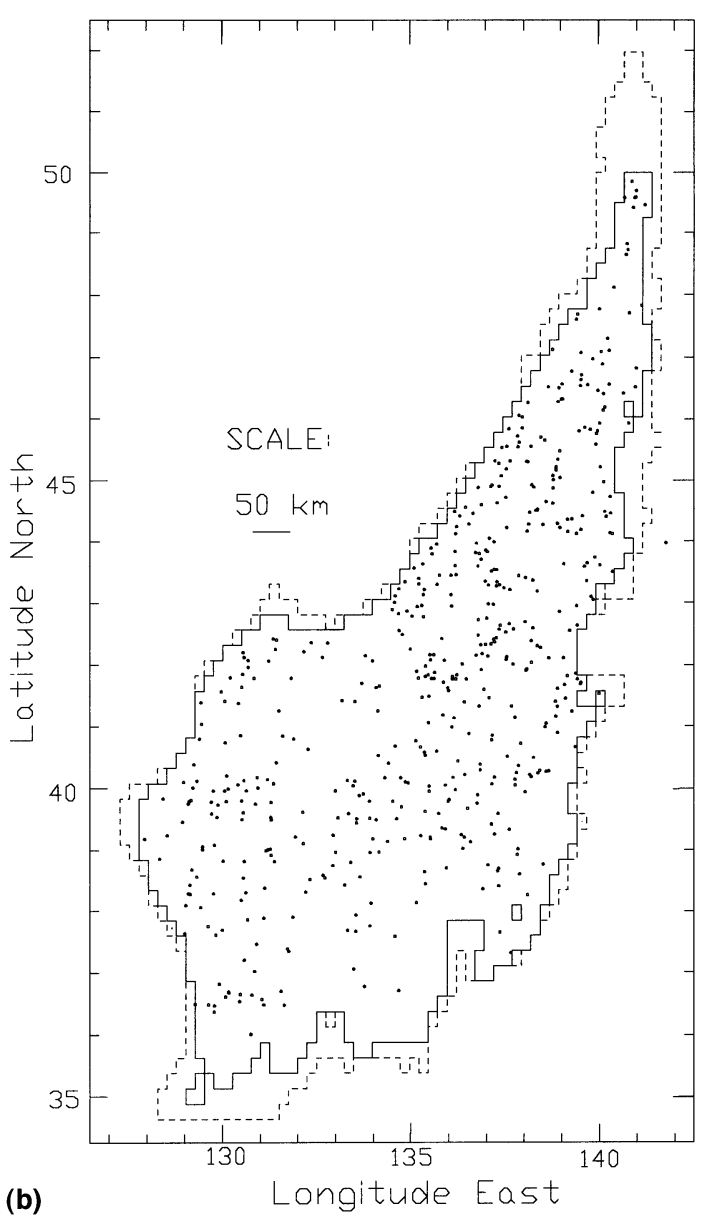

Figure 9. Simulated transport-dispersion of particles, with topostress taken into account $(L=4 \mathrm{~km})$ : 9000 particles released in 90 days from the dumping site 9; (a) layer 12 (depth 100-180 m), after 5 years; (b) layer 12 after 30 years; (c) layer 16 (depth $0-10 \mathrm{~m}$ ) after 30 years 


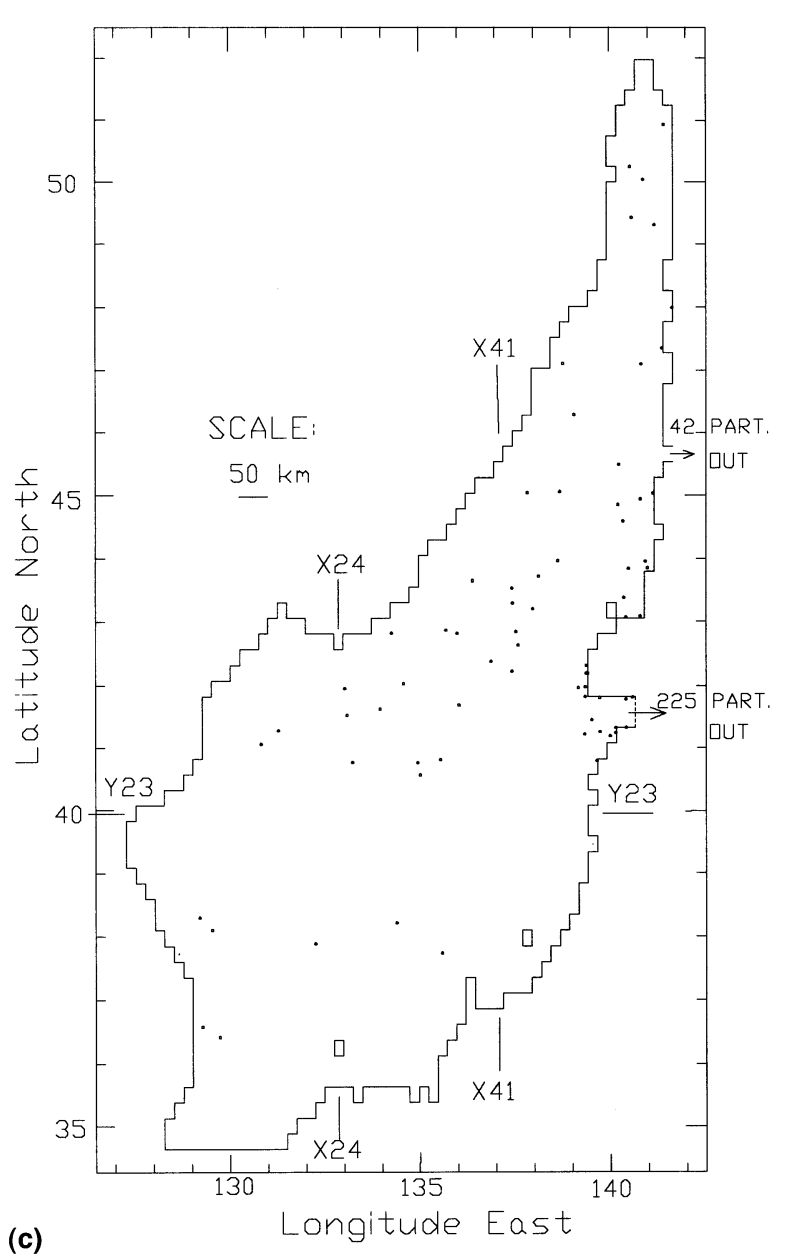

Fig. 9. (Continued)

\section{CONCLUSIONS}

The following conclusions can be drawn from the results:

- Besides the study of the possible radionuclide contamination, the present research is also an attempt to contribute some new information on the hydrodynamic and pollutant dispersion processes in the Japan sea, and on the effect of topographic stress in the ocean circulation modelling.

- Comparison of the simulated velocity fields with observed surface and subsurface currents and with some measurements of bottom currents in the Japan Sea has shown relatively good verification of the 3D hydrodynamic model PCFLOW3D.

- The main forcing factor, influencing the bottom circulation in the Japan Sea is thermohaline forc-

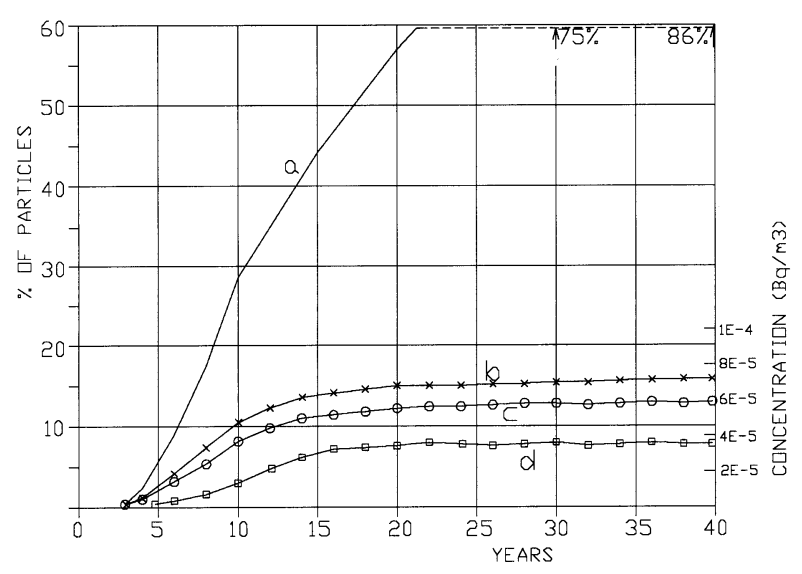

Figure 10. Transport of particles from the bottom $(Z=-3500 \mathrm{~m})$ through the level $Z S=-180 \mathrm{~m}$ (in \% of the total number $=$ 9000 ). Scale for concentration is valid only for curves $c$ and d. (a) Number of particles once passing the $Z S$ level; (b) sum of particles situated above the $Z S$ level and particles which have been transported out of the Japan Sea through the Tsugaru and Soya straits; (c) particles situated above the $Z S$ level at a given time; (d) particles situated above the $Z S$ level-computation without topostress.

ing due to strong temperature and salinity gradients. It can cause bottom velocities up to about 10 $\mathrm{cm} \mathrm{s}^{-1}$, which is confirmed by measurements. Influence of the wind forcing is an order of magnitude smaller, although it can influence the surface circulation.

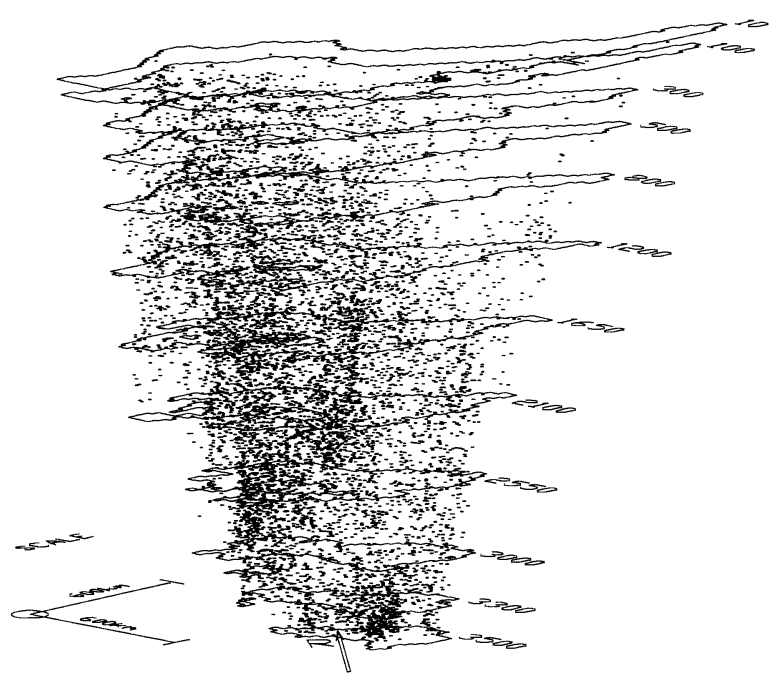

Figure 11. Three-dimensional view of particles' distribution after 5 years, with $L=4 \mathrm{~km}$. Location of the release marked by R. 


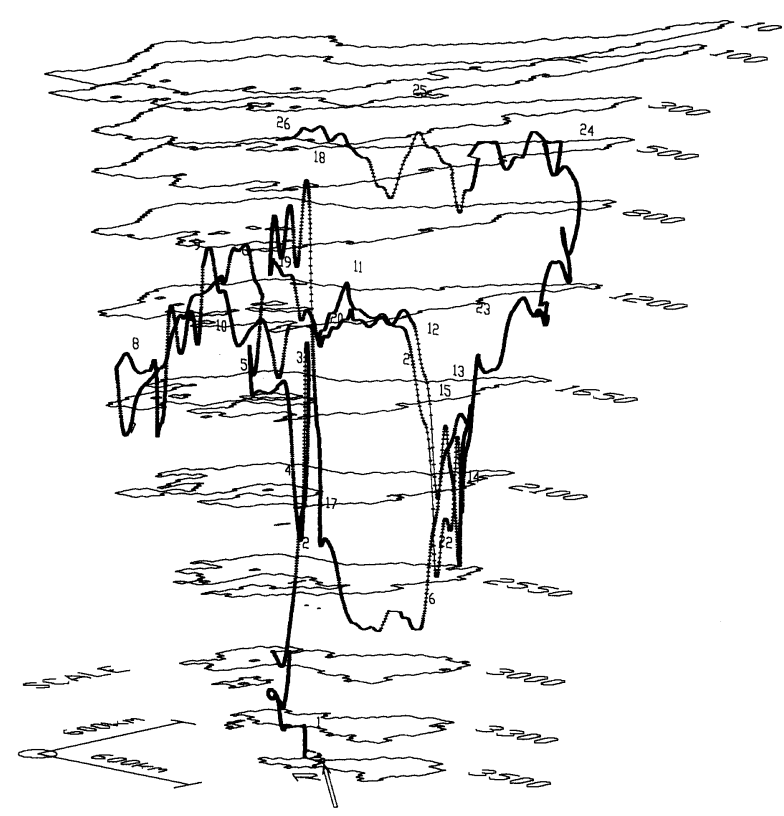

Figure 12. 3D view of 12 years' trajectory of one particle. Start of the simulation is at the beginning of the winter season. The numbers only mark the direction of the particle's movement. The positions of the particles (small circles) are marked at each time step of $D t=0.5$ days.

- The simulated hydrodynamic field in the Japan Sea is in visibly closer agreement with the observed surface circulation when the topographic stress is taken into account in the modelling.

- The final results, i.e. the transport-dispersion of radionuclides which could possibly leak from the containers at the dumping sites at the sea bottom, show the following features: some first, very small contamination would reach the surface layers (above $180 \mathrm{~m}$ depth, where fishing is possible) after about three years. The maximum concentrations, which would be about $10^{-2} \mathrm{~Bq} \mathrm{~m}^{-3}$ for the supposed leaking scenario, would be attained after twenty years, but after 30 years already $96 \%$ of the maximum concentration would be attained. But everywhere the radionuclide contamination would be about two orders of magnitude smaller than the present background values. Therefore, the estimated radiation doses to the local population will be negligible (Togawa et al., 1999).

\section{Acknowledgements}

This work was carried out during R. Rajar one year stay at the International Atomic Energy Agency (IAEA) in Monaco. The work was partly funded by IAEA Technical contract No. 8847/ RB/TC. Development of the PCFLOW3D model was supported by the Slovene Ministry of Science and Technology with several contracts. IAEA-MEL operates under a bilateral agreement between the IAEA and the Government of the Principality of Monaco.

\section{REFERENCES}

Četina, M., Rajar, R., Širca, A., 1996. Development and implementation of a computer code for modelling the disperion of radioactive pollutants around damping sites, Research project for the Intern. Atomic Energy Agency, M.E.L., Monaco, Contract $8847 / \mathrm{RB} / \mathrm{TC}$

Eby, M., Holloway, G., 1994. Sensitivity of a large-scale ocean model to a parametrisation of topographic stress. J. Phys. Oceanogr. 24, 2577-2588.

Gamo, T., Horibe, Y., 1983. Abyssal circulation in the Japan Sea. J. Oceanogr. Soc. Japan 39, 220-230.

Hellermann, M., Rosenstein, J.T., 1983. Normal monthly windstress over the world ocean with error estimates. J. Phys. Oceanogr. 13, 173-187.

Hirose, K., Amano, H., Baxter, M.S., Chaykovskaya, E., Chumichev, V.B., Hong, G.H., Isogai, K., Kim, C.K., Kim, S.H., Miyao, T., Morimoto, T., Nikitin, A., Oda, K., Pettersson, H.B.L., Povinec, P.P., Seto, Y., Tkalin, A., Togawa, O., Veletova, N.K., 1999. Anthropogenic radionuclides in seawater in the East Sea/Japan Sea: Results of the first-stage Japanese-Korean-Russian expedition. J. Environ. Radioactivity 43, 1-13.

Holloway, G., 1992. Representing topographic stress for largescale ocean models. J. Phys. Oceanogr. 22, 1033-1046.

Holloway, G., Sou, T., Eby, M., 1995. Dynamics of circulation of the Japan Sea. J. Mar. Res. 53, 539-569.

Ikeuchi, Y., Amano, H., Aoyama, M., Berezhnov, V.I., Chaykovskaya, E., Chumichev, V.B., Chung, C.S., Gastaud, J., Hirose, K., Hong, G.H., Kim, C.K., Kim, S.H., Miyao, T., Morimoto, T., Nikitin, A., Oda, K., Pettersson, H.B.L., Povinec, P.P., Tkalin, A., Togawa, O., Veletova, N.K., 1999. Anthropogenic radionuclides in seawater of the Far Eastern Seas. Sci. Total Environ., S.I. The Marine Environment-Understanding and protecting for the future 237/238, 203-212.

Isobe, A., Tawara, S., Kaneko, A., Kawano, M., 1994. Seasonal variability in the Tsushima current, Tsushima-Korea strait. Cont. Shelf Res. 14 (1), 23-35.

Ketchum B.H. (Ed.), 1983. Ecosystems of the World 26: Estuaries and Enclosed Seas, Elsevier, pp. 375-383.

Kim, H.C., Yoon, J.H., 1996. Modeling of the wind-driven circulation in the Japan Sea using a reduced gravity model. J. Oceanogr. 52, 359-373. 
Koutitas, C., O'Connor, B., 1980. Modelling three-dimensional wind-induced flows. J. Hydraul. Eng. ASCE 106, 1843-1865.

Levitus, S., 1982. Climatological atlas of the world ocean. NOAA Profess. Paper 13, U.S. Dept. Commerce.

Lie Heung-Jae, Byun Sang-Kyung, 1985. Summertime southward current along the East Coast Korea, J. Ocean. Soc. Korea 20, $2,22-27$.

Lie Heung-Jae, Suk Moon-Sik, Kim Cheolcho, 1989. Observations of southeastward deep currents off the east coast Korea, J. Oceanol. Soc. Korea 24, 2, 63-68.

NOAA, U.S. Department of Commerce, 1994. World Ocean Atlas, CD No.1: Objectively Analysed Temperature fields, CD.2, Objectively Analysed Salinity Fields.

Patankar, S.V., 1980. Numerical Heat Transfer and Fluid Flow. McGraw Hill B.C., New York.

Peterson, H.B.L., Balestra, S., Baxter, M.S., Gastaud, J., HuynhNgoe, L., Liong Wee Kwong L., Parsi, P., Province, P.P., 1995, Radionuclide analysis of samples from the 1994 JapaneseKorean-Russian expedition to the Sea of Japan, Rep. Int. At. Energy Agency, M.F.I., Monaco.

Povinec et al. (in preparation).

Rajar, R., 1989. Three-dimensional modelling of currents in the northern Adriatic Sea. Proc. of the XXIII Congress Intern. Assoc. Hydraul. Res. Ottawa.

Rajar, R., 1995. Modelling of disperion of radioactive pollutants in the Japan Sea. Rep. Int. At. Energy Agency, M.F.L., Monaco.

Rajar, R., 1997. Modelling of circulation and dispersion of radioactive contaminants in the Japan Sea, Proc. Intern. Symp. on Circulation research of the E. Asian marg. seas (CREAMS), Fukuoka, Japan, pp. 363-366.

Rajar, R., 1998. Transport of sediments from Mururoa lagoon into ocean. Chapter 3.2. In: The Radiological Situation at the Atolls of Mururoa and Fangataufa: Main Rep. Int. At. Energy Agency, Vienna, pp. 177-179.

Rajar, R., Četina, M., 1997. Hydrodynamic and water quality modelling: An experience. Ecol. Model. 101, 195-207.

Rajar, R. Četina M., Žagar, D., 1995. Three-dimensional modelling of oil spill in the Atlantic. Wrobel, L.C., Brebbia, C. (Eds.), COASTAL 95, Proc. Int. Conf. Can-Cun, Mexico, pp. 95, 102.
Rajar, R., Četina, M., Širca, A., 1997. Hydrodynamic and water quality modelling: case studies. Ecol. Model. 101, 209-228.

Rajar, R., Žagar, D., Širca, A., Horvat, M., 2000. Three-dimensional modelling of mercury cycling in the Gulf of Trieste. Sci. Total Envir. 260, 109-123.

Rodi, W., 1980. Turbulence models and their application in hydraulics-A state-of-the-art review, IAHR Publ., Delft.

Seung, Y.H., Yoon, J.H., 1995. Robust diagnostic modeling of the Japan Sea circulation. J. Oceanogr. 51, 421-440.

Širca, A., 1992. Modelling of Pollutant Transport with the Particle Tracking Method. Thesis, M.Sc. University of Ljubljana, Fac. Civil Geodetic Enginrg. (in Slovene).

Širca, A. Rajar, R., Horvat, M., Harris, R.C., 1999. Mercury transport and fate in the Gulf of Trieste (N. Adriatic)-a-twodimensional modelling approach. Environ. Model. Soft. 14, $645-655$.

Togawa, O., Povinec, P.P., Pettersson, H.B.L., 1999. Collective dose estimates by the marine food pathway from liquid radioactive wastes dumped in the Sea of Japan. Sci. Total Envir. S.I. The Marine Envir. Understanding and protecting for the future $237 / 238,241-248$.

Tsunogai, S., Watanabe, Y.W., Harada, K., Watanabe, S., Saito, S., Nakajima, M., 1993. Dynamics of the Japan Sea deep water studied with chemical and radiochemical tracers, Deep Ocean Circul., Phys. Chem. Aspects, Elsevier, 105-119.

Watanabe, Y.W, Watanabe, S., Tsunogai, S., 1991. Tritium in the Japan Sea and the renewal time of the Japan Sea deep water. Mar. Chem. 34, 97-108.

Yoon, J.H., 1995. Numerical Modeling of the Ocean Miniature "Japan Sea". Proc. Intern. Workshop on Num. Prediction of Ocean Variations, Tokyo, pp. 105-121.

Yoon, J.H., 1991a. The branching of the Tsushima current, 1991. Rep. Instit. Appl. Mechanics 38, 1-21.

Yoon, J.H., 1991b. The seasonal variation of the East Korean warm current. Rep. Instit. Appl. Mechanics 38, 23-36.

Zavatarelli, M., Mellor, G., 1995. A numerical study of the Mediterranean Sea circulation. J. Phys. Oceanogr. 25, 13841414. 